\title{
Why FX Risk Management Is Broken - And What Boards Need to Know to Fix It
}

Håkan Jankensgård, Alf Alviniussen and Lars Oxelheim 


\title{
Why FX Risk Management Is Broken
}

\section{- And What Boards Need to Know to Fix It}

\author{
This version: 2015-07-29
}

\author{
Håkan Jankensgård ${ }^{\mathrm{a}}$, Alf Alviniussen ${ }^{\mathrm{b}}$ and Lars Oxelheim ${ }^{\mathrm{c}}$
}

\begin{abstract}
In this paper we challenge the role of Foreign Exchange Risk Management (FXRM) in corporate management. We believe it is fair to characterize FXRM, on the whole, as a legacy activity rather than something that reflects a realistic cost-benefit analysis at the enterpriselevel. The Board of Directors, as the designated guardians of the interests of shareholders, has a key role in setting the firm on a path towards a cost-efficient and centralized FXRM that preserves the firm's transparency and predictability towards the investor community. A policy conclusion from our analysis is that responsibility for FX policy should shift from the traditional Finance/Treasury orientation to a group risk function (e.g. a Chief Risk Officer) supported by a risk committee dedicated to integrated risk management.
\end{abstract}

Key words: Foreign exchange, risk management, transparency, risk committee, integrated risk management.

JEL code: G30, G32

a

Corresponding author. Assistant professor at the Department of Business Administration and Knut Wicksell Centre for Financial Studies, Lund University. Address: P.O. Box 7080, 22007 Lund, Sweden. Telephone: +46 46222 4285. Email: hakan.jankensgard@fek.lu.se. Jankensgård gratefully acknowledges the financial support of the Jan Wallander and Tom Hedelius foundation.

b

Independent consultant and former Senior Vice President and Group Treasurer with 42 years of employment with the Norwegian conglomerate Norsk Hydro ASA. Alviniussen has had the responsibility for the overall risk management of the group as one of his responsibilities. He is also a member of the Bank Stakeholder Group with European Banking Authority, London.

C

Professor at the Department of Business Administration, Knut Wicksell Centre for Financial Studies, Lund University, Sweden and School of Business and Law, University of Agder, Kristiansand, Norway. Affiliated researcher at the Research Institute of Industrial Economics, Stockholm, Sweden. Oxelheim gratefully acknowledges the financial support of the NasdaqOMX Nordic Foundation

The authors would like to thank Tom Aabo, Niclas Andrén, David Carter, and participants at the 2015 FMA Applied Finance, New York, for valuable comments. 


\section{Introduction}

In one of its recent quarterly reports, a large Scandinavian industrial company disclosed a foreign exchange (FX)-related loss to the tune of USD 200 million. While not deadly to the company, the loss appeared to be serious. This can be appreciated by considering the size of its reported net income before financial items, which in the same quarter was about USD 60 million. The reported loss had several and complex causes, but most of it was due to revaluation of balance sheet items, including derivatives and other off-balance sheet items. Revaluation of external and internal loans and intercompany accounts had a major impact, and these effects were to a large extent incurred in cross currency rates not involving the home currency of the company. The single most important contributor to the currency effect was internal loans given from a EUR-based subsidiary in USD to subsidiaries with accounting in a third currency. As a consequence, the FX loss was largely not cash effective, but rather represented what should be seen as 'paper volatility', in this case largely created by transactions within the corporate group.

The above paragraph serves to illustrate some fundamental truths about Foreign Exchange Risk Management (henceforth FXRM) ${ }^{1}$ : it is a very complex issue which may have a substantial impact on the firm's reported net income, cash flow, equity and other financials. In a globalized economy few firms are able to escape FX exposures of some kind entirely. Given this, one might well ask the following question:

\footnotetext{
${ }^{1}$ The standard textbook definition of FXRM encompasses the activities of managing the currency composition of the firm's debt and the hedging of FX exposures using derivatives. A broader definition of FXRM would include also the management of the currency composition of the firm's future cash flows, including the choice of production facilities, sourcing of raw materials, and so on. We define FXRM as a process that, in addition to these activities, comprehends the quantification of exposures to FX risk as well as the communication of FX risk to investors.
} 
- Are companies' FX risks, given their financial expertise and the sometimes substantial resources dedicated to FXRM, generally well managed, thus contributing to the fulfilment of corporate objectives?

For a surprisingly large proportion of firms, our answer to this question is no. In fact, we argue that FXRM is broken and suggest six reasons - introduced in Section 2 of this paper - why most existing FXRM programs are to be seen as substantially flawed. The root cause of the gap between what is and what should be done seems to be that the complexity of organizations, as well as that of the global economic environment, have outpaced companies' ability to deal with them. To a significant degree FXRM can be considered a legacy activity, much in the same way that the legendary corporate leader Jack Welsh characterized corporate budgets: they only exist in their current form because they have been institutionalized.

In this normative and policy-oriented paper we argue that the costs of a poorly conceived FXRM have increased in a world that rewards transparency and lean organizations. In our view, firms' Board of Directors should rethink the FXRM function and how it is organized, as well as attempt to clarify the costs and benefits of this activity. Representing the owners of the firm, i.e. the shareholders, the Board of Directors have the ultimate responsibility for monitoring the firm's business activities, and for overseeing its risk taking. It is the duty of directors to ensure that the firm has a sound process in place for managing risk, and that the firm's managers are not wasteful of the organization's resources. Current FXRM practices are often a liability on both these accounts, and directors are in a unique position to provide the impetus for change.

Boards of Directors often lack detailed insights that are important in order to understand key issues related to global FX exposure management in an international firm. This normally 
prevents them from acting as agents of change. Due to the technical complexity of derivatives and financial markets, it has long been considered appropriate to delegate the management of FXRM to the treasurer or specialists in the finance department (henceforth referred to as Finance/Treasury). This division of labor contributes to preserving the status quo. In this article we survey academic work on risk management with the goal of guiding Boards of Directors in the process of rethinking and challenging FXRM as applied today. We identify six dimensions that are likely to capture the essence of a cost-benefit analysis. A more detailed cost-benefit framework is, in our view, not feasible and in any case not desirable for our purposes. The devil is not in the details: our ambition is to take a step back and provide a critical look on how FXRM fits into the bigger picture of corporate management.

From our analysis emerges a vision of FXRM as an activity that uses up few resources and does not clutter financial reports. FXRM is strictly centralized, and business units are instead focusing on the operating activities that they do best. In our vision the FX policy is no longer owned by Finance/Treasury, but is one of many risk policies owned by a corporate risk function and actively supported by a risk committee dedicated to integrated risk management, taking into account the total risk of the company. In our vision, FX exposures are well understood and quantified, making surprises infrequent. Executive compensation, as well as the measurement of business unit performance, are unaffected by windfalls created by changes in exchange rates or other macroeconomic risks beyond management's control. FX derivatives are largely avoided, not least those that concern smaller transactions. FX hedging, when it does occur, mitigates an exposure to FX risk that is quite simply considered unacceptable when the overall financial standing and performance of the company is evaluated. 
This paper is organized as follows. Section 2 lays out the six reasons why we believe FXRM is broken. Section 3 discusses how the goals of FXRM can be re-framed. Section 4 illustrates various ways the firm can implement a centralized approach to FXRM. Section 5 discusses how to align performance evaluation with FXRM. Section 6 presents ideas on how to improve decision-support tools in relation to FXRM. Section 7 contains a discussion on how to integrate FXRM into a framework for integrated risk management. Section 8 discusses how to improve risk communication. Section 9 concludes the paper.

\section{Six reasons why FXRM is broken}

In what follows we present six dimensions of FXRM for which we argue that firms' current practice is systematically flawed. Our arguments may apply primarily to organizations that are above a certain size, and therefore associated with a considerable level of complexity. However, we claim that most multinational firms meet this restriction and thereby fall well within the scope of the analysis. In fact, many of the challenges associated with FXRM are typically present also in small and medium-sized firms (Oxelheim and Wihlborg, 2008).

The argument that FXRM is broken may seem to suggest that there was a time when it was not. As companies began to internationalize their operations on a far greater scale in the 1960s and 1970s than they hitherto had, they had to learn about the effects of fluctuations in exchange rates and find ways to protect their cash flow and profit margins from these swings (the demise of the Bretton Woods Agreement in 1971 pushed companies in this direction, and the final breakdown of the Smithsonian Agreement in March 1973 was the definite trigger). Remaining ignorant about these issues would have appeared unacceptable to most executives, which thus legitimized building up the relevant financial and technical expertise in FXRM. As FXRM has implied close contacts with banks in the execution of spot and forward transactions, short term 
currency funding, payment processing and other cash management and bank related activity, it was natural to place the responsibility for FXRM and interest rate risk management with Finance/Treasury. Typically, companies opted to analyze these risk exposures separate from each other, cementing them into so-called "risk management silos”, which is a commonly used term for describing a risk management activity that is not managed in an integrated way. In part, this separation was driven by the artificial stability induced by fixed-exchange rate arrangements.

Over time, however, more complex accounting rules, more elaborate cross-border business models, a stronger demand for transparency, and the emergence of a holistic risk thinking has implied that a rethinking and a reorganization of the FXRM function is needed. In what follows we describe how these different trends have led many existing FXRM-approaches to underperform in at least six important respects: objective setting, integration, centralization, performance evaluation, quantification, and communication.

\subsection{Lack of clear objectives}

As the example in the introduction indicated, the complexity of FX risk exposures can be mindboggling. With activities in dozens of countries, conducted through a multitude of legal units and business units, in an endless stream of transactions of varying character, on top of which comes a bewildering set of accounting rules, firms are faced with a reality that is a far cry from the stylized examples in finance textbooks, in which a firm typically executes a single hedge based on a clearly defined exposure. Against this background, it should not come as a surprise that many companies are unsure as to what the ultimate purpose of FXRM should be. In practice, the issue is often framed in terms of 'hedging cash flows or net income'. While 
academic research tends to favour cash flow ${ }^{2}$, there is an ingrained feeling in many managers that net income should be stabilized and protected from volatility in the financial markets. By convention considered as "the" bottom line, net income continues to have a special standing as a measure of performance in the business community.

The special role afforded to net income may be changing, however, in part as a result of the notorious IAS $39^{3}$, which is the accounting standard that contains the rules concerning how financial instruments should be carried in the books for firms adhering to International Financial Reporting Standards (IFRS). The standard mandates that derivatives are to be “marked-to-market”, and that the resulting unrealized gains or losses are to be shown in the net income statement. IAS 39 is an application of fair value accounting, the principle that accounting numbers should reflect 'fair' market values. However, marking-to-market a derivative position is liable to increase volatility in net income, because the underlying exposure being hedged is not allowed the same treatment. This is the glaring inconsistency of current accounting standards. ${ }^{4}$ It is inevitable that a performance measure thus affected by the whims of accounting standards will lose its meaningfulness as a hedging objective. This confounds many managers, who usually agree to the basic sense of protecting cash flows, yet feel that they cannot simply ignore the effects on net income because of its traditional importance.

The 'hedging cash flows-or-net-income'-dichotomy is only part of the story, however. Over the years we have registered a large number of motivations for hedging a certain risk exposure. Box

\footnotetext{
${ }^{2}$ We will come back to a more detailed description of academics' recommendations in Section 3.

${ }^{3}$ IAS 39 is to be replaced in 2018 by IFRS 9.

${ }^{4}$ The effect on net income can be avoided if the hedge qualifies for "hedge accounting", in which case the gain or loss is moved to an equity reserve without affecting net income. The problem with hedge accounting is that the rules are arcane and complying with them means dedicating substantial and many times unreasonable resources to the task.
} 
1 lists 20 of these. While there is some overlap, we believe they represent qualitatively different motives for hedging. These reasons for hedging can exist simultaneously in an organization and enjoy different levels of support depending on time and place. This creates tensions and the preconditions for conflict over corporate policy. It is indeed striking how each argument can be made to sound convincing and legitimate depending on the framing of the situation. To illustrate, we have listed just two in Box 2. When various and diverse motives are allowed to impact FX hedging the result is a largely ad-hoc, oversized, and unpredictable form of FXRM. What is lacking in many companies is a clearly articulated rationale for FX hedging that spells out why, from the enterprise-perspective, a particular FX exposure should be considered unacceptable. A well articulated logic for determining what is unacceptable, however, is required to guide and create consistency in the firm’s FXRM over time, not least considering the often strong tendency for local agendas to drive demand for FX hedging (see section 2.3).

\subsection{Lack of risk management integration}

The push towards integrated forms of risk management is one of the clearest trends in this area over the last couple of decades (Aabo et al, 2005; Nocco and Stulz, 2006; Lundqvist, 2014). One virtue about integrated risk management is that it involves managing the firm's risks on a portfolio basis, taking correlations and off-setting exposures between risk factors into account when deciding risk management policy (e.g. Alviniussen and Jankensgård, 2009). Yet integrated risk management remains an elusive goal for many companies. Organizational rigidities and local incentives to preserve the status quo often stand in the way of a successful implementation (Alviniussen and Jankensgård, 2014). Another impediment is the lack of decision-support tools capable of presenting an integrated view of the firm's risk exposures (Alviniussen and Jankensgård, 2009). 


\section{Box 1 Reasons for using derivatives}

1. Avoid bankruptcy

2. Avoid not having enough funding for the optimal level of investment

3. Lower the risk of downgrade

4. Secure access to a loan

5. Lower the risk of covenant breach

6. Avoid having to make asset fire sales

7. Stabilize the dividend of subsidiary

8. Stabilize capital expenditure outlays

9. Avoid plant closure

10. Secure a profit margin in a commercial deal

11. Stabilize the level of cash flow

12. Stabilize the level of net income

13. Secure an average market price for a product

14. Lower 'volatility' because investors dislike it

15. Stabilize the book value of equity (translation of subsidiaries)

16. Stabilize the value of inventory

17. Compensate for impairment loss of asset

18. Lock in a "good" price (i.e. "beating the market)

19. Achieve "stability" to focus on operating performance

20. Avoid hostile take-over

\section{Box 2 All arguments for hedging can be made to sound plausible}

"One of our subsidiaries is going to pay a large dividend in USD in a few months. That amount represents value built up over many years. It would be terrible if a large portion of that wealth creation would be wiped out due to a change in the exchange rate between now and the payment date. We should hedge this dividend to ensure we obtain the value that has been created!”

"We are looking at a major investment over the next two years. A significant share of the outlays will be in a foreign currency. If the exchange rate moves we will be facing a much higher investment cost and a lower return. A lot of people are putting their hearts into this project and it would be distressing if it seemed to suffer poor returns only because the exchange rate moved. We should hedge these outlays to make sure this project does not end up below break-even!” 
The difficulty of achieving integrated risk management can be illustrated by the simple case of commodity producers based outside the U.S. Since commodities are typically priced in USD, these firms tend to have two clearly identifiable exposures that make up a large portion of their overall cash flow volatility: the exposures to the commodity price and the exchange rate between USD and its home currency (in which a high portion of costs are normally incurred and in which performance is normally measured). This seems to be the ideal setting to achieve an integrated form of risk management - one that considers the risk profile of both these exposures and the way they co-vary over time. However, not all commodity producers achieve it. In fact, in many cases the management of FX risk, typically under the discretion of the treasurer, is still considered a distinct task from price exposure management. This separation means that, in the jargon, FXRM is a "silo". Often, FX exposures are also not integrated with other closely related macroeconomic risks, such as interest rate exposures. It can even be argued that there are silos within the FX silo. For example, FX exposures related to cash positions often are looked at separately from the exposures arising from, say, accounts receivables and payables.

\subsection{Lack of centralization}

By decentralized FX hedging we mean an arrangement in which business units can decide on their own hedging strategy and/or carry out derivative transactions directly with banks (Jankensgård, 2015). Conventional wisdom, however, holds that firms should centralize FXRM. A centralized approach facilitates the netting of exposures, thereby saving on transaction costs compared to hedging gross exposures. Also, by pooling the company's FX exposures headquarters usually obtains stronger bargaining power vis-à-vis banks and can therefore negotiate better rates than each business unit could individually. 
We argue that a decentralized approach to FXRM indeed carries substantial disadvantages. Apart from those already mentioned, a decentralized approach implies that an extra layer of staff and systems devoted to FXRM are maintained throughout the organization. Furthermore, it implies a larger risk that something goes wrong, either by mishandling or by unauthorized speculation. Business units concentrate not on what they are supposed to be doing - improving operations, cutting costs, boosting sales, and so forth. Instead, they devote precious time and resources to financial management. Even worse, business units may be tempted to take views on the future directions of exchange rates in order to profit from their hunches. A potential cost arising from this lack of co-ordination is that total risk is actually increased by off-setting naturally hedged positions within the firm. The final stage of FXRM fragmentation occurs when business units hedge individual sales (and/or purchase) orders, leading to a large number of relatively small transactions. ${ }^{5}$ Despite these drawbacks, survey evidence indicates that decentralized hedging is commonplace (Edelshain, 1997; Belk, 2002; Jankensgård, 2015).

\subsection{Lack of alignment between FXRM and performance evaluation}

One of the major recent debates concerning the governance of companies is executive compensation. Over the last couple of decades executive compensation has rocketed. Executive compensation began growing at a faster rate in the mid-1970s (Frydman and Saks 2010) and the general upward trend is since then well established (Wells, 2012). Efforts by regulators to put a cap on compensation have failed (Murphy, 2012). Featuring large in this debate has been the fact that executives have earned handsomely thanks to factors beyond their control (Oxelheim et al, 2012). Executive compensation schemes tend to be asymmetrical in the sense that executives are rewarded more for good performance than they are punished for bad.

\footnotetext{
${ }^{5}$ While this review of decentralized hedging is decidedly negative, we acknowledge that this approach is not entirely without potential benefits. One advantage, mentioned in Oxelheim and Wihlborg (2008), occurs when locally held knowledge about finance facilitates the correct pricing of business deals. One such example concerns correctly taking into account the interest rate differentials between two countries.
} 
In this setting where the CEO will benefit from FX tailwind but is not punished for FX headwind the CEO has incentives to opt for bigger than optimal-for-the-firm FX-exposures (Chiu et al, forthcoming). In addition, allowing FX fluctuations to affect the compensation of the Chairman of the Board may also make the Chairman abandon his obligations and bond with the CEO in his/her net income management efforts (Oxelheim and Clarkson, forthcoming). As a consequence, investors and boards may not be able to correctly assess the company's level of sustainable profits. The problem with the noise created by FX windfalls extends to the relationship between business units and headquarters. Fluctuations in exchange rates may, in much the same way, distort business unit performance and unduly punish or reward their management for fluctuations beyond managers' control. A failure to align FX risk management practices and the firm's performance evaluation systems lies at the heart of many of the troubles associated with FXRM today.

\subsection{Lack of appropriate tools for FX risk quantification}

Making sound FX hedging decisions presupposes that exposures to FX risk have been quantified in a reliable and consistent way. Our point in this section is that many companies use tools and techniques for quantification that do a poor job predicting actual exposures. Such firms may therefore experience frequent surprises and make hedging decisions that exacerbate rather than limit the volatility of financial performance.

Quantifying the FX risk exposure on operating cash flows may seem like a straightforward thing. And it may be, so long as one is content to measure it as the difference between expected cash inflow and cash outflow in a particular currency ('transaction exposure') and for a given time horizon (e.g. 6 months). A serious shortcoming with this approach is that the short-term 
transaction exposure may be a poor indicator of operating cash flow exposures over a longer period, such as a year or more. Transaction exposures, for example, do not capture competitive effects. A firm without any transaction exposure or any cash flows or positions denominated in foreign currencies may still be outcompeted in its home market due to a real exchange rate change “subsidizing” the foreign competitors’ entry on that very market (Oxelheim and Wihlborg, 2008). For even moderately-sized companies, the complexities of FX exposures can be massive and therefore defy quantification by simplistic analytical approaches (Andrén, Jankensgård, Oxelheim, 2005).

Quantification becomes even more complicated when exposure is defined in terms of net income. Net income exposure to FX is a function not only of operating exposure, but also the impact of FX on net finance costs, which captures interest expenses (net of income) and various revaluation effects from financial items in the balance sheet. This is where we enter the arcane worlds of accounting for cross-border transactions that we caught a glimpse of in the first paragraph of this paper. The rules that cover this area have to do with the treatment of monetary items denominated in a currency other than the firm's functional currency, and fair value accounting, i.e. the idea that certain assets and liabilities should be carried in the books at a value that tracks their actual or perceived market value. Simple structures are conceivable, such as the firm that borrows solely in its home currency, does not enter into any financial contracts denominated in foreign currencies, or has one single loan in a foreign currency. But, as indicated earlier, such simplicity is the exception for multinational firms and. Today loans, swaps, and derivatives that involve foreign currencies are ubiquitous, giving rise to quarter-toquarter FX revaluation effects that can be of considerable magnitude. When these effects are poorly understood management will experience frequent surprises and make decisions based on assumed future scenarios for net income that may be wide off the mark. 


\subsection{Lack of effective risk communication}

According to some theories, a firm should be rewarded for disclosing more information and becoming more transparent through an increased liquidity of its shares and a lower cost of capital (see Botosan, 2006, for an overview). An understanding of key risk exposures is essential input for analysts and investors when making scenarios to support valuations and resource allocation decisions. For example, a report by CFA (2011) found that 90\% of analysts find risk disclosures useful and use them in company evaluations. Despite this value-relevance, firms are liable to underperform with regard to FX risk disclosure in one of two main ways: by disclosing too much, or by disclosing too little. Both carry its own set of problems and lead to a higher-than-necessary cost of capital (Forssbaeck and Oxelheim, 2015).

First let us take a look at the problem of too much disclosure. The growth in the number of data points disclosed in annual reports has been exponential over that last couple of decades (EFRAG, 2012; Jankensgård, 2014). According to Oxelheim (1999) investors may have difficulty making sense of all the detailed disclosure and “drown in a flood of information”. Equally colorfully, the EFRAG report describes disclosure overload as a problem of "not seeing the wood for all the trees”. It is not hard to see how FXRM fits into this picture. FX derivatives are subject to onerous accounting rules, and many firms engage in detailed and complex voluntary disclosures about their derivative positions. According to Jankensgård et al (2014) this is problematic for at least three reasons. First, disclosure about derivatives, though intended to reassure investors about management's oversight and control, may in fact make the company seem more risky through a "salience effect". ${ }^{6}$ Second, investor sentiment towards FX risk disclosure may in fact be fundamentally negative since it clutters financial reports and thus makes it harder to assess underlying performance. Third, by disclosing a great deal of

\footnotetext{
${ }^{6}$ Taylor and Thompson (1982) define the salience effect as follows: "'Salience refers to the phenomenon that when one's attention is differentially directed to one portion of the environment rather than to others, the information contained in that portion will receive disproportionate weighting in subsequent judgments.',
} 
information about its derivative positions, a company may draw attention to a potential problem: that managers use derivatives for purposes that are not driven by shareholder value maximization.

The problem of too little FXRM disclosure is partly driven by the current accounting standards. These standards mandate that firms report exposures related to financial instruments, not the FX exposures of the underlying business (Oxelheim and Thorsheim, 2014). As a consequence, disclosing the sensitivity of total performance to FX risk, which is what investors presumably find useful, is largely voluntary from the company’s perspective and often missing. In a study of the 100 largest European firms for 2000-2010, Oxelheim and Thorsheim (2014) find that no guidance useful to the outside stakeholder on the role of windfall gains for the sustainable profits is provided by any of the firms. Nor do firms reliably supply investors with information that provide guidance on the principles behind their risk management. Jankensgård et al (2014) find, in their sample of listed Swedish firms, that only half of them clearly state the firm's FX hedging policy. When such information is lacking, a firm's hedging activities are largely unpredictable.

\section{The way forward}

Where does one start when implementing a FXRM program, or overhaul an existing one? It would seem that a proper place to start is to ask: What is the overall goal of FXRM supposed to be? What do we want to use it for? We offer no definite answers to these questions. What is the most sensible goal of FXRM may differ from company to company, and even from time to time in the same company. What we do propose, however, is a set of steps for determining if a company currently has any FX exposures that are unacceptable to it, and therefore require risk mitigation. 
To arrive at what constitutes an unacceptable FX exposure, FXRM must be re-framed. As discussed previously, in many companies minute FX derivate transactions flourish, driven by local incentives, such as protecting a particular receivable in foreign currency. We argue that FXRM needs instead to be considered in the broader context of a firm's strategies and its financial position (and how these influence each other). In order to produce a sensible answer to the question of 'why manage FX exposures?' boards and senior managers should analyze carefully how FX exposures impact the firm’s ability to meet future cash commitments and important strategic and financial objectives. What we mean by 'in the context of strategies and financial position' will become clear later in this paper.

For now we note that the question of how FXRM contributes to firm value cannot be ignored. At the end of the day, managers work on behalf of the firm's owners, and should seek to maximize firm value (within the boundaries and constraints that are put on the firm by society and other stakeholders). This means that FXRM must have a 'business case', which every organization should make as explicit as possible. According to academic models, the potential for risk management to create value comes primarily from its ability to protect the firm from disruptive lower-tail outcomes (Aabo, 2015). ${ }^{7}$ Negative consequences of such lower-tail outcomes include bankruptcy (Smith and Stulz, 1985), underinvestment (Froot, Scharfstein, and Stein, 1993), or asset fire sales (Hagströmer and Jankensgård, 2011). These academic models have the following implication: a low and deteriorating level of liquidity indicates a more pressing need to engage in FXRM, especially if the balance sheet is also weak, thus limiting future borrowing. This “distance-to-default”-framework is a useful point of departure for any discussion on the pros and cons of a risk management program.

\footnotetext{
${ }^{7}$ More specifically, Aabo shows that a variance-minimization strategy may be suboptimal because it might, under certain assumptions, increase the likelihood of a costly lower-tail outcome.
} 
Putting these concepts into actual practice, Jankensgård (2010) analyzes how non-financial firms can conceptualize and measure their risk profile by establishing meaningful reference points, or thresholds, for measuring risk. These thresholds are “doomsday” levels of performance which the firm should not go below because it would entail serious consequences. A critically low level of liquidity is an intuitive reference point. But risk would depend also on the state of the firm's balance sheet in that scenario. A strong balance sheet can facilitate access to new capital so that problems are avoided, whereas the same liquidity situation may translate into costly adjustments if the balance sheet is weak. A risk measure designed to capture downside risk should therefore be a function of both liquidity and a measure of the health of the firm's balance sheet. Two concrete examples in this regard are the thresholds for key financial ratios at which the firm's debt covenant is breached, or at which the firm's debt is downgraded by credit rating agencies. The Board of Directors should monitor how far the company is from breaching the specified thresholds and understand how FX fluctuations impact that probability. Such risk measures might indicate what constitutes an unacceptable exposure to FX risk (or any other risk for that matter).

The take-home from academic work on the rationale for corporate hedging is that it generally only pays off hedge if there is some negative and disruptive consequence of cash flow volatility that can be avoided, such as leaving the company unable to execute the business plan. Fluctuations in performance may seem dramatic and bad to managers, but investors generally hold fairly diversified portfolios, and these ups- and downs tend to smooth out. So, contrary to our intuition, managing the swings in the profit and loss-statement is not necessarily a legitimate objective, given that risk management is costly. Diversification on part of the 
investors means that they care largely about expected mean, not volatility (unless some of the negative consequences of volatility discussed above are present).

Our tendency not to appreciate this point might be referred to as the "volatility-is-always-bad"fallacy. We do not subscribe to the view that volatility is always and everywhere a bad thing. In fact, trying to stabilize net income per se only makes sense if investors and analysts actually place a premium on lower net income volatility. It is a questionable proposition that FXRM can contribute in this regard. In fact, with the advent of fair value accounting the net income measure is even at risk of losing its relevance altogether. A striking aspect of the FX inducedloss discussed in the first paragraph of this paper was that few cared or even took notice about the FX loss, despite its magnitude. ${ }^{8}$ There is a relentless focus on operating performance among analysts and investors, and, lacking evidence to the contrary, we believe that it is a delusion to assume that value is created by stabilizing the net income when current accounting standards make this figure so arbitrary. The burden of proof to produce a "business case" should lie squarely on the individuals that propose a hedge that aims at protecting against a loss for its own sake. ${ }^{9}$

To summarize this section, firms should escape the curse of the "volatility-is-always-bad"fallacy and instead look for threshold levels of aggregate performance, the breaching of which is truly unacceptable because it brings some additional negative consequence (over and above the loss itself). These threshold levels should be the "anchors" of the risk management program

\footnotetext{
${ }^{8}$ A strongly contributing reason for this was that the company interpreted the loss to signify a positive future impact on commercial cash flows from the change in the exchange rate. This had been duly communicated through FX sensitivities, serving to underscore the importance of risk communication.

${ }^{9}$ In practice, such "business cases" tend to be nothing more than arguing that "we believe exchange rate X is going to fall”. Unless the board is convinced that these individuals have a clear and sustainable competitive advantage in predicting the macro-economy such view-driven hedging should be reined in substantially.
} 
and guide risk management policy. ${ }^{10}$ Norsk Hydro, an Oslo-based aluminium-company, can serve as example. They structured their financial management around two financial ratios (netdebt to equity and funds from operations to debt) which were believed to be the focus of credit rating agencies. The threshold levels were defined as those levels at which it was likely that a downgrade would occur, which was considered an unacceptable outcome by management. When the firm implemented a firm-wide program for quantifying and managing risk these levels became the reference points for measuring and communicating risk.

\section{Climbing the centralization-ladder}

It is a useful exercise to diagnose FXRM as it looks in the company today. Questions that could be used to guide such an inquiry include: What motives lie behind the various FXRM-activities going on in the company (FX hedging in particular)? Whose best interest do they serve? What are the actual costs and benefits of this activity? What would happen if we simply stopped all of it tomorrow?

From a diagnosis of the reasons why FX hedging is carried out in the company the following conclusion is more likely than not to emerge: much of it is driven by incentives that are decidedly local in nature, as opposed to being based on an assessment of what is in the best interest of the company as a whole. One unit wants to hedge the investment outlays in a foreign currency to protect the return on investment of that project. Another unit wants to hedge the sales from a poorly performing plant to avoid that senior management closes it if the profitability drops even further. And so on. We would go as far as to say that FX hedging today,

\footnotetext{
${ }^{10}$ A potentially problematic aspect of this approach is that if this approach becomes anticipated, the mere fact of announcing a hedge could lead investors to assume the firm is doing worse than they had previously thought and to revise their forecasts of the firm's performance negatively. That is, the hedge could become a signal of a higher likelihood of future financial difficulties. In turn, this could have consequences for the firm's ability to obtain new funding. Such a signalling effect may, to some extent, off-set the positive effect from the hedge itself.
} 
in many companies, cannot be explained without a reference to the incentives of particular individuals at different levels in the organization. The human element in FX hedging is large and significant. This is a problematic state of affairs because FXRM, thus conceived, will be uncoordinated, ad-hoc, and unpredictable.

Since the drawbacks of decentralized FX hedging are real and substantial, the firm's Board of Directors should set it on a path to climb up the "centralization-ladder", which is depicted in Figure 1. As it moves up the ladder, central control is gradually strengthened. Few will argue against the benefits of concentrating bank contacts to headquarters so that the company can enjoy better rates and other benefits from a strategic, long-term relationship with the banks chosen at the corporate level. A decentralized FX hedging combined with a central control could in principle be obtained by a so-called 'internal hedging'-arrangement, under which business units are free to hedge, but only with headquarters as counterpart. Headquarters then only makes the external hedges that it finds appropriate.

While internal hedging is an improvement, our recommended approach would also involve giving little or no discretion to business units in terms of deciding their own hedging policy. Business units should focus their attention on the operating issues that they do best and leave financial management entirely to headquarters. Centralizing financing and hedging is, after all, one of the most obvious benefits from establishing a corporate group in the first place. Taking centralization to the extreme, Holmen, an USD 8bn Swedish manufacturer of paper and pulp, executes a hedge centrally based on a FX policy set by headquarters. Its various business units then receive "their share" of this external hedge through internal hedging contracts so that $100 \%$ of the hedge is allocated. That leaves no residual exposure from the hedge in the parent company, and there is perfect consistency between its internal and external hedges. 
Management has to be realistic about the fact that decentralization may be the outcome of a 'power grab' by strong and independent-minded business units who are used to, and like, deciding on all aspects of 'their' business. This situation may make it decidedly tougher to implement centralization. ${ }^{11}$ In overcoming this problem, companies may be inspired by the example of Statoil, a USD100bn oil and gas producer based in Norway. They have relentlessly pursued a policy of central control over market risks, including FX risks. An important aspect of their success in doing so comes from the fact that headquarters did their homework on what the corporate policy should be, and defining headquarters as the "owner” of all market related risks like oil and gas prices, FX, interest rates etc. Once they had made up their minds and designed a risk policy that made sense from Statoil's perspective as an enterprise, they set about implementing it. Armed with a clear idea about what risk management should be in Statoil they were in a much better position to face down resistance to a centralized policy. This is an important insight that is very relevant in the context of FXRM: think through what the corporate policy should be, and how it is supposed to create value, and then stand firm in implementing it.

Above all, there should be only one FXRM-philosophy/policy in the company: that which is endorsed by the board and senior management. FXRM has to be robustly top-down. Proposals to hedge, or other forms of risk mitigation, whether they originate in business units, trading units, or the finance department, have a tendency to crop up based on an analysis from the perspective of that unit and then travel upward in the company for approval. Unless

\footnotetext{
11 Sometimes business units may resent the loss of autonomy implied by centralization. However, based on our experience, and talks with many managers on this issue, this is a problem that passes relatively quickly. Business units come to adapt to the new situation with centralized FXRM, and may even find the existence of a corporate policy useful and convenient. When a business unit does hedging on its own and mistakes or large losses occur, they may find themselves questioned and blamed. With a corporate policy in place, they can claim they simply followed policy. Life becomes a little easier
} 
headquarters are committed to a particular policy with regard to FXRM, it is easy to be won over by the arguments underpinning the proposal, which no doubt will sound quite convincing.

Figure 1: Different degrees of headquarter control

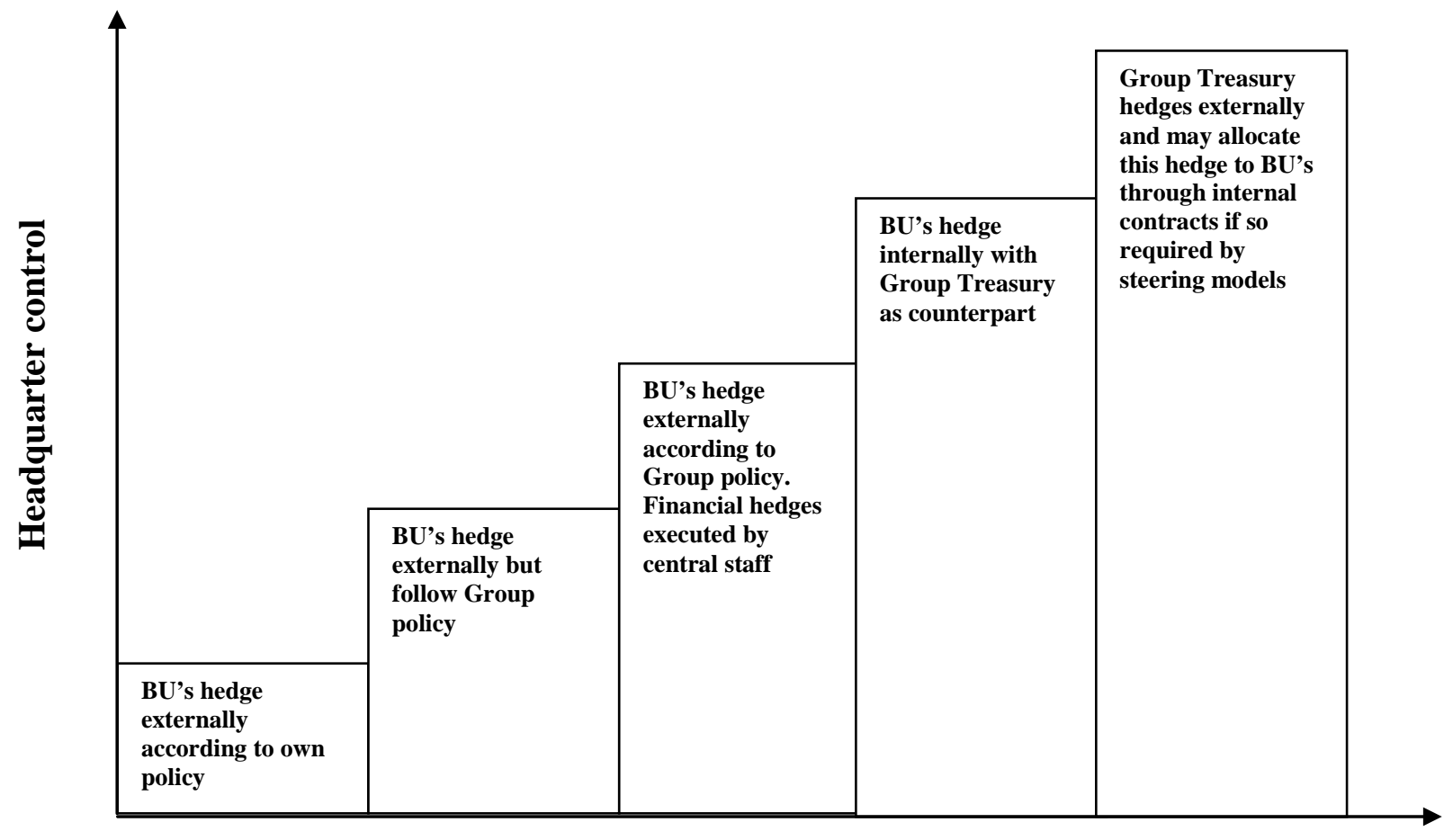

Approach to currency exposure management

\section{Getting performance measurement right}

Centralizing FXRM solves some important problems but leads to a set of new, though lesser, ones. As noted earlier, business units have what seems to be a justified right to be able to manage risk exposures that affect their performance, on the basis of which they are evaluated and the unit's management rewarded. Centralization of FXRM implies that this right is taken away or at least severely restricted, which may lead to discontent. One of the central ideas of 
this paper is that one cannot reshape FXRM without also reconsidering the way that performance is measured and bonuses are granted. Let us have a look at how this can be achieved.

The most attractive long-term solution is to eliminate the demand for FX derivatives by removing its impact on the performance of the business units altogether. A case in point is the retail industry. In retailing companies the parent company, which usually also is the production unit, sells the goods produced to its marketing units in their own functional currency. Since their revenues are in local currency they are unexposed to FX risk in terms of their cash flow and obtain a balance sheet free from nominal currency effects. Any currency exposure ends up with the parent company, creating the preconditions for centralized FXRM. Another approach is to replace monetary performance measures - EBIT, net income, etc. - with measures tied more closely to operating performance. Boliden, a USD 5bn Swedish mining company, has gradually over the years implemented this shift, and their business units have become evaluated solely on their ability to improve operations, i.e. the efficiency and reliability of the mining facilities. As a consequence of redirecting focus from monetary performance measures to operating ones, FX hedging is a non-issue in these units.

However, in some companies shifting the focus to non-monetary operating measures of performance in order to eliminate the demand for FX hedging (or hedging of commodity prices) in the business units may not be easy. Monetary measures like EBIT remain a cornerstone in many performance evaluation systems. What is desired in these cases is a way to filter out the impact on the business units' EBIT from changes in exchange rates, so that what is obtained is a clean measure of operating performance. Some companies attempt something like this by calculating what EBIT would have been if the assumptions about FX rates in the corporate 
budget had actually come true. In our experience such attempts are rarely successful. A more promising approach is the Macroeconomic Uncertainty Strategy (MUST) developed by Oxelheim and Wihlborg (2008), who argue that exposures to macroeconomic risk can be captured by applying regression analysis on the relevant corporate performance measure.. The regression approach quantifies a neutral, average statistical relationship between exchange rates and corporate performance, while controlling for other macroeconomic factors to which the company is exposed (e.g. interest rates, inflation rates, and commodity prices). For any given time period the firm can use these sensitivities to calculate what EBIT would have been if exchange rates had not changed (see Box 3). A MUST-analysis of CEO compensation in Swedish public firms in the period 2000 up to the financial crisis reveals that about $60 \%$ of the bonus increases during the period can be traced to macroeconomic tailwind (Oxelheim, Wihlborg and Zhang, 2012). 


\section{Box 3 The MUST analysis}

An analysis according to The Macroeconomic Uncertainty Strategy (MUST), (Oxelheim and Wihlborg, 2008) has three pillars: fundamental analysis, multivariate estimation, and hedging strategy formulation. Assume that the analysis results in the following matrix for a German firm selling in the US, while competing there with a Swiss firm. The firm follows a policy of no FX hedging.

\begin{tabular}{|l|c|c|}
\hline Variable & Macro change & Sensitivity coefficients \\
\hline EURO/USD & $5 \%$ & $3 \%$ \\
US 3m interest rate & $1 \%$ & $-3 \%$ \\
Swiss producer prices & $2 \%$ & $1 \%$ \\
\hline
\end{tabular}

The firm experiences an actual performance increase of 8\%. Good or bad? Does the firm experience a macroeconomic tailwind or headwind? The answer is that the firm has wasted the help from a macroeconomic tailwind of $14 \%$ (the effects in the table are additive, so we get $5 * 3+1 *(-3)+2 * 1=14)$.

In fact, the firm has lost $6 \%$ of its sustainable performance, i.e. its competitiveness (estimated as 14-8).

Instead of being seduced by the $8 \%$ performance increase, the board should be informed about the actual magnitude of the macroeconomic tailwind, and the alarming development of the firm's sustainable profits.

\section{Improving decision-support tools}

We argue that FXRM should achieve more by doing less, i.e. it should be an activity that consumes few resources and generates little complexity in pursuit of well-defined objectives. One potential cost-reduction measure has to do with eliminating the firm's internal process for generating FX sensitivities. In many companies there is a heavy bottom-up machinery for quantifying and reporting these exposures. Not only is this activity consuming resources, it is quite likely leading to erroneous exposure estimates anyway. As discussed in Section 2.5 
corporate FX exposures are bewilderingly complex and influence on the company’s performance through a variety of channels. In addition, business units may have a poor understanding of the exposure concept and use different definitions of it. The combination of complexity and inconsistent methodology leads to a predictable outcome: estimated FX sensitivities that are incorrect.

Instead of a bottom-up approach for quantifying operating exposures we recommend the MUST regression-based approach for these purposes as well. The regression approach has the advantage that the quantified relationship captures the net effect of all the firm's exposures, which are often so complex that bottom-up approaches are bound to fail. It is therefore a very useful tool for dealing with the complexity of corporate exposures to macroeconomic risk. It has the added benefit of being very cost-effective, once established. Under this approach for quantifying exposures, a company can do away with the entire process of estimating, collecting, and assembling exposure estimates from various parts of the organization.

While a resource-light FXRM is the goal, in one area we argue that it is warranted for companies to use a bit more resources than most currently do: the modelling of the firm's forecasted financial position. Having a high degree of knowledge about one’s exposures, and how they affect various financial parameters like net income, liquidity, and the balance sheet, is essential to professional business conduct. Incurring a loss can be fine so long as the possibility of such a loss was known in advance and considered acceptable by management. Experiencing few surprises is the true yard-stick. Also, gaining this knowledge makes it easier to communicate and explain FX effects in net income to analysts and investors, which has turned out be a challenge to companies in today's environment. 
In practical terms, achieving this involves two challenges: forecasting the net finance costs and the firm's balance sheet in such a way that they reflect underlying FX exposures. In contrast to operating exposures, for which we advocate the MUST-model, for these two pieces of modelling an analytical bottom-up approach usually makes sense. The line 'Finance items' in the net income statement captures net interest expense plus the realized and unrealized effects from various FX denominated balance sheet items including financial instruments used to hedge the operating exposure. ${ }^{12}$ It is important to model it adequately, or else we will only get part of the FX picture. Modelling finance items correctly calls for what we term a 'matrix approach'. In this approach it is recognized that a) an exposure only exists if an asset or liability is denominated in a currency different from the reporting currency ${ }^{13}$ of the legal unit which owns it and b) exposures due to such a mismatch can occur also on internal transactions, i.e. between different legal units in the same group (see Box 4). Many people feel the latter point is counter-intuitive. Internal transactions ought not to matter because, well, they are internal. But accounting rules have it this way: the company may have to report in its consolidated net income effects that arise due to revaluing loans between the parent and a subsidiary. ${ }^{14}$

We also suggest that the entire forecasted balance sheet be made FX sensitive in a way that reflects actual accounting principles. The way this is done is by modeling the so-called Currency Translation Adjustment (CTA). The CTA is an equity reserve that equalizes the FX exposures that affect the net income statement with what they need to be for the company as a whole given the net asset-liability position, i.e. the difference between its assets and liabilities denominated in different currencies (see Box 5). One of the function of the CTA is to "undo"

\footnotetext{
${ }^{12}$ Effects from revaluing monetary balance sheet items like trade receivables and payables will typically also be reported in Finance costs.

${ }^{13}$ Also referred to as the base currency, accounting currency or reference currency of the subsidiary.

${ }^{14}$ The firm's total equity is not affected by these internal transactions, however, which is more in accordance with our intuition. The profit- and loss effect is neutralised by a change in an equity reserve (the Currency Translation Adjustment, CTA, to be discussed below).
} 
the net effect on equity from P\&L effects created by internal transactions (otherwise the FX effects on these transactions would affect the firm's total equity, which is an unacceptable proposition). But it also keeps track of the "real” revaluation effects created by a mismatch between asset and liabilities in different currencies, or what is typically referred to as the firm's ‘translation exposure’.

One might claim that this is just accounting and therefore does not really matter. Well, again we emphasize the need for a deep and correct understanding of one's FX exposures in order to experience few surprises. Also, the firm's definition of an unacceptable exposure may involve a financial ratio or performance measure that is affected by these revaluation effects. It is therefore a good idea to have the balance sheet forecasts, and the financial ratios derived from them, reflect actual exposures when considering different exchange rate scenarios for the future. A correctly specified model may help the company understand how likely it is, say, that a target level for a financial ratio is breached due to the exposures that have been quantified (including then translation exposures), and how different risk management strategies will affect this risk. 


\section{Box 4 The matrix approach to quantify exposures}

The matrix approach is a way to quantify the degree to which net income is exposed to revaluation effects on monetary assets and liabilities in its balance sheet (monetary assets and liabilities are those with contractually defined payoffs, such as debt and trade receivables). It recognizes that exposures only arise when the transaction currency of the monetary asset or liability of different from the base currency of the legal unit holding it. It also recognizes that consolidated net income may be impacted by the revaluation of assets and liabilities that are internal to the company (e.g. a loan given by the parent company to a subsidiary). The goal is to map out these exposures in a matrix where the transaction currency appears on one axis and the base currency of the legal unit on the other axis. This information can then be integrated into the firm's financial forecasting tool to accurately predict net income under various scenarios for exchange rates.

As an example, consider a Swedish parent company with two subsidiaries, one in Sweden and one in Belgium (which consequently has EUR as its base currency). The Swedish subsidiary exports to the US and therefore wants to borrow in USD to off-set this exposure. The Belgian subsidiary's sales are EUR-denominated and it wants to match that exposure by borrowing in EUR. The parent company borrows externally in SEK and USD and then arranges internal loans to its subsidiaries. Let us assume that the parent borrows SEK 500 and USD300 million from banks. The loans to the subsidiaries are USD 110 and EUR200 million respectively. At the balance sheet date, the company would organize this information into the following matrix.

\begin{tabular}{|c|c|c|c|}
\hline \multirow[t]{2}{*}{ Base currency } & \multicolumn{3}{|c|}{ Transaction currency } \\
\hline & SEK & USD & EUR \\
\hline SEK & -500 & -300 & 200 \\
\hline USD & & & \\
\hline EUR & & & -200 \\
\hline
\end{tabular}

The key aspect of the matrix is that everything that appears on the diagonal - when the base currency coincides with the transaction currency - is not exposed. The mismatches off the diagonal are exposures whose revaluation effects will have to be reported in consolidated net income, regardless of whether they pertain to internal or external transactions. In this case, the USD bank loan is fully exposed since neither the parent nor the SEK-subsidiary has USD as base currency. (The exposure related to the loan in the Swedish subsidiary of USD 110 mill is set off by a corresponding asset in the parent) The EUR loan in the Belgian subsidiary is not an exposure, since it represents a liability that will be carried in accounts that are EUR-denominated. From the perspective of the parent company, however, the loan is an asset (a financial receivable) that will be exposed to changes in the EUR/SEK exchange rate because the transaction and base currency are different. These effects will have to be reported in consolidated net income despite being based on an internal transaction. The SEK loan is FX neutral in the Swedish parent. 


\section{Box 4 The currency translation adjustment (translation exposures)}

The matrix approach outlined in Box 3 is useful because it allows the firm to correctly quantify the impact on consolidated net income from changes in exchange rates. While this information may be sufficient for some firms, other firms may also consider modelling the FX exposures of the whole forecasted balance sheet so as to obtain correctly predicted financial ratios to support decision-making. If this is not done, the FX effects from the matrix, while correct in terms of net income, will incorrectly affect the forecast of the firm's consolidated equity. To see this, assume that the EUR/SEK exchange rate increases by $0.1 \mathrm{SEK}$. Then the financial receivable (the loan to the Belgian subsidiary) will be worth SEK 20 million more. This gain will increase consolidated net income and by extension equity with the same amount. This increase in equity is unacceptable, however, because it implies that the gain or loss from an internal transaction could impact the firm's net worth. The Currency Translation Adjustment (CTA) is an equity reserve whose function it is neutralise any such gains and losses from currency mismatches on internal transactions.

The CTA also captures the net effect on equity from the difference between assets and liabilities in a given currency (now we are talking about all assets and liabilities in foreign currency, not just the monetary ones). We refer to this difference as the Net Asset-Liability Position, which specifically excludes internal transactions because they always cancel out. Assuming that the subsidiaries hold no foreign-denominated assets on their own, the only assets the firm in our example from Box 3 has in EUR correspond to those of its Belgium-based subsidiary. We assume that these assets (e.g. plant, property, and equipment) are EUR400 million. The USD-debt of 300 million is the firm's only item exposed in USD since it has no subsidiary whose assets are denominated in that currency. The exposed Net Asset-Liability Position of the company is therefore (million):

$\begin{array}{lccc} & \text { Non-monetary items } & \text { Monetary items } & \text { Net Asset-Liability } \\ \text { EUR } & 400 & & 400 \\ \text { USD } & & -300 & -300\end{array}$

In the end, the translation-induced effect on equity from an exchange rate change has to be that dictated by the Net Asset-Liability Position. The job of the CTA is to reconcile the matrix of exposures in Box 3 with the Net Asset-Liability Position shown above. For this computation we utilize the column Non-Monetary Items in the table above (monetary items are already affecting equity through net income). The information to complete the CTA calculation is found in the diagonal in the exposure matrix in Box 3: we have to use this information to undo the effect on net income from internal transactions.

Again assuming a SEK 0.1 increase in EUR/SEK, this would cause the 400-asset to be worth SEK 40 million more, which goes into the CTA (without affecting net income). However, there is a 20 million gain in net income (see Box 3) that also will increase equity for a total increase of 60 . We therefore define the CTA to include the revaluation of the items on the diagonal in the matrix, or -20 in this case. The CTA will therefore increase only by 20 , and net income by 20 , for a total equity increase of 40 . This coincides with the effect implied by the Net Asset-Liability Position, which was required for internal consistency. 
As part of its quest to pursue integrated and cost-efficient risk management we also recommend that companies embark on a strategy of "from several models to one" and that this unified decision-support tool contains "risk-adjusted" forecasts, i.e. forecasted financial statements that reflect the firm's knowledge about its risks (see Box 6). It is not uncommon for a company to operate several decision-support tools that, in one way or another, are related to FXRM. For example, there may be models for forecasting the budget, liquidity developments, or FX exposures specific to near-term monetary transactions. In our experience, pooling the companies' competence in this area into a single, unified decision-support tool can yield substantial benefits. At the end of the day, all of these activities are interrelated.

The goal is therefore to develop an integrated financial model that can be used to support decision-making in a wide range of areas, including top-level strategic decision-making concerning e.g. the capacity to grow and invest. Adequate decision-support is obtained when the model is risk-adjusted, and can provide an adequate and correct representation of the effect of the proposed corporate policy on the firm’s risk-return profile. Thus we have returned to one of the key points made earlier in this paper, namely that FXRM needs to be considered in the context of the firm's strategic and financial objectives. When FX policy is set in this context it is with a view to how FX risks impact the firm's overall risk profile, thus shifting the focus away from viewing FX exposure management in a narrow profit-and-loss context. 


\section{Box 6 Integrated risk modelling}

As an example of a company that has embarked on a "from several to one"-project at group level, consider again Norsk Hydro (see Alviniussen and Jankensgård, 2009). At one point this company decided that it would be better off replacing the near-constant reconciling and error-checking of its various financial applications with a single, integrated financial model that could be used to support decision-making in a wide range of areas, including top-level strategic decision-making concerning e.g. the capacity to grow and invest. One of the features of this model is that it contains a detailed and internally consistent description of the FX exposures that affect the firm's EBIT, finance items and balance sheet (i.e. the matrix modelling and the CTA). In each risk scenario the firm's financials is recalculated according to IFRS accounting principles in such a way that the model "self-balances", i.e. there is no unexplained residual or plug. The fact that everything hangs together from an accounting point-of-view greatly increases the quality of the forecasts, and the faith decision-makers can have in their reliability.

The Norsk Hydro decision-support tool models not only FX risks but other risks as well. In fact, the model describes the company's exposures to a large number of other risk factors, such as interest rates and product prices. The way these risks tend to co-vary, or correlate, is taken into account. This integrated modelling allowed the diversification benefits of correlated risks to be quantified and to influence the assessment of total risk. For example, the price of oil and aluminium are strongly correlated with the Norwegian Krone, which lowers total risk.

From where should the required inputs be found in order to obtain "risk-adjusted" forecasts, i.e. forecasted financial statements that reflect the firm's knowledge about its risks? The MUST-model discussed in the previous section covers a variety of other macroeconomic risk factors. Such an exposure-model contains all the necessary information for a modelling of aggregate cash flow risk while retaining the exposureinformation required for hedging decisions. Andrén, Jankensgård and Oxelheim (2005) show, using Norsk Hydro as a case, that such a model can be applied to form the basis of a Monte Carlo-simulation of the firm's expected future performance and risk. A Monte Carlo simulation generates, say, 10,000 scenarios for its main financial parameters, making it possible to overcome the limitations of the typical static trio of "bestexpected-worst” scenarios, and instead obtain a whole range of probability-weighted outcomes (i.e. a probability distribution). These simulations take into account correlations as well as dynamic aspects of the firm's risk exposures. In cases where the firm has implemented a program for integrated risk management, or Enterprise Risk Management (ERM), the necessary input may come from its so-called risk register, or risk map. The risk register is basically a list that describes the firm's main risks according to the likelihood that they happen and the severity of their impact. Firms that create an interface between its risk register and its financial forecasting tool obtain riskadjusted forecasts. 
What we are discussing is essentially a fusing of the firm's financial planning process and its risk management program, including FXRM. In previous work, we have labelled such an approach Enterprise Risk Budgeting (Alviniussen and Jankensgård, 2009). In ERB, the firm’s financial forecasts are risk-adjusted and therefore capable of generating feed-back on the firm's total risk profile. As an example of such a feed-back, consider a firm that has a targeted debt-toequity ratio that it considers unacceptable to breach. An ERB decision-support tool can report on the probability of such a breach. This estimate will reflect not only the risk exposures affecting its cash flows, but also the health of the firm's financial position (i.e. its balance sheet). Importantly, the ERB decision-support tool can report this probability under various different corporate policies. What if we increase our investment budget? What if we hedge one of our main exposures? What if we borrow in USD rather than our home currency? How will risk be affected? Managers can then choose the policy that leads to the most attractive riskreturn trade-off given its risk appetite. As argued by Alviniussen and Jankensgård (2013), by implementing ERB a firm’s risk management, financial planning and strategic decision-making become integrated processes.

\section{Re-organizing FXRM}

The arguments we have put forth so far in this paper lead to an important question: if FX risk is to be managed in an integrated way, with a view to the risk-return of the company as a whole, then which part of the organization should “own”, or be responsible for, the FX policy? We can immediately answer who it should not be: the finance department, or treasury, because this will tend to preserve a narrow focus. This puts the traditional organizational logic on its head since for as long as anyone can remember the FX policy has been shaped and handled by the Finance/Treasury department. We posit, however, that this arrangement needs to be reconsidered if the benefits of an integrated form of risk management are to be realized. 
Who then should be the steward of the firm's FX risk policy if Finance/Treasury is ruled out? To answer this question, we first note that the Board of Directors has a fiduciary duty to oversee the firm's activities, including risk management. Board members should therefore take an active interest in the firm's overall risk management processes, and promote an approach that is cost-effective and consistent with the best interest of shareholders rather than driven by local agendas. However, the received division of labor dictates that the board does not get involved in the actual running of the company. Instead, the most promising route to implementing an integrated form of FXRM is through a chief risk officer (CRO) supported by a risk committee, or the equivalent function responsible for the firm's total risk. The risk committee is typically formed by various senior managers, such as the CFO, the CFOs of business units, representatives from business units dealing with risks, the chief risk officer, the treasurer, the chief legal officer, the head of the planning department, and so on. This is a forum where difficult risk-related questions can be discussed and resolved, and where the various interests of the organization can be balanced, but where the interest of the company as a whole ultimately prevails. This committee is typically not vested with executive powers but remains a decisionsupport forum, reporting to the executive responsible for the firm's overall risk management (e.g. the CRO or CFO).

Statoil offers a useful example of integrated risk management (Alviniussen and Jankensgård, 2014). There, the chief risk officer and his team have gradually managed to turn the risk committee into a champion of Enterprise Risk Management. Though no executive powers have been vested in the committee, it is the real authority and arbiter on risk-related issues. Any major risk-related issues need to pass the committee, where the pros and cons are weighted from the perspective of the company as a whole. As a result, decisions on risk are much less 
driven by local agendas, and the outcome reflects to a lesser extent the idiosyncrasies of certain powerful individuals. The FX policy in Statoil is no exception.

What we propose is that the old model of an FX policy owned by Finance/Treasury be replaced by one in which the risk committee has a decisive role. This is not to say that Finance/Treasury will be excluded from the process. On the contrary, they have much expertise that is necessary for a risk committee, and ought to have a permanent seat on it. Likewise, a well performing Finance/Treasury is probably the most apt department for operating an integrated decisionsupport tool of the kind we discussed previously. This unit will also continue to have the responsibility for executing and managing the various transactions related to FXRM. But what needs to change is the mind-set and framework for deciding policy related to FXRM. FXRM is not to be considered an activity best left to FX dealers who know about the financial markets. They are indeed the best to do the transaction part of the FX risk management process. FX policy and risk mitigation issues, however, should to be thought of as part of an enterpriseportfolio of risks, where the contribution of FX exposures to the firm's total risk profile is in focus.

\section{Getting risk communicating right}

Firms that implement a cost-effective, centralized, and integrated FXRM will find that it creates many benefits. Even when one's own house is in order an important task remains: communicating this to the outside world. This is in order to achieve a beneficial effect on the firm's cost of capital from the increased credibility and reassurance that a well-designed FXRM brings. As we discussed in section 2.6, firms tend to get risk communication wrong in two ways: either by disclosing too little (not providing the relevant information) or by disclosing too 
much (cluttering the financial reports). In unfortunate cases, firms get in wrong on both accounts simultaneously.

What we advocate first and foremost is that the Board of Directors and senior management start viewing risk communication as a strategic goal under their direct purview. It is not something that should be delegated to people in the accounting or finance department, or decided by consultants in a local context. Since the firm's transparency is at stake, which in turn impacts on the cost of capital, it is much too important to be left unmanaged.

The guiding principles for disclosure are that it should be clear, simple, and useful. Equally important is that disclosures appear in the appropriate context. A useful example concerns the exposures related to FX derivatives. On their own and out of context, these disclosures can be nearly useless, especially if they are voluminous and complex.

We posit that the typical analyst or investor is interested in four sets of facts. The first is a quantitative estimate of the sensitivity of the firm's operating performance to changes in exchange rates (which can be quantified using the MUST-methodology outlined earlier). The second is the corresponding estimate of the sensitivity of the firm's portfolio of financial instruments. The third is the net of these two estimates, i.e. the firm's net sensitivity to changes in exchange rates, using which the analyst can calculate the net performance impact under different FX scenarios. The fourth is some kind of qualitative description of the firm's overall hedging policy, i.e. the thinking and philosophy that guides its risk mitigation actions. Above all, FXRM needs to achieve a modicum of predictability. Not being able to foresee the actual exposures and how the firm might act in the future adds to the impression of clutter and frequent surprises. 
Are disclosures over and above these four essentials always wrong? Clearly not. But we do advocate restraint. More disclosure is far from always better, given the drawback discussed in section 2.6: lower overall transparency, an impression of higher riskiness, and a heightened concern about the amount of resources devoted to FXRM. Investors, it seems, generally want predictable pure plays they can understand, and not some mysterious cocktail of different derivative instruments.

\section{Conclusions}

We have argued that FXRM can be viewed largely as a legacy activity, the cost-benefit balance of which continues to go unscrutinised and unquestioned in many companies. The costs of FXRM have gone up in recent decades because of the increased demand from investors and analysts for cost-efficiency, transparency, and predictability. The inherent complexity of FXRM and the arcane accounting rules it obeys make it problematic from these perspectives, especially considering that some firms do not seem to have a coherent hedging policy. Instead, in many companies FX hedging is fuelled by local incentives of an ad-hoc nature, which in the end have little to do with the best interest of the firm as a whole. In these cases FXRM becomes largely opaque and unpredictable.

We have advanced six important dimensions in this paper to address these problems. One of these is that FXRM should be a minimalistic, resource-light activity that revolves around the basic goal of mitigating FX exposures that are simply unacceptable to the company at the enterprise level. An exposure becomes unacceptable when a case can be made that the consequences of certain scenarios for exchange rates would entail decidedly negative consequences, such as a breach of a debt covenant or having insufficient liquidity to execute the 
business plan. Firms should seek to escape the curse of the "volatility-is-always-bad”-fallacy, which occurs due to the (usually false) intuition that variability in profits and losses are inherently bad, even on the level of business units, projects, or individual transactions. Diversified investors, we posit, would rather have the company maximize the expected return on assets by focusing on core operating activities.

A main conclusion of the paper is that the traditional organization of FXRM may need to be reconsidered. Historically, the responsibility for the FX policy has resided with the Finance/Treasury department, a fact which has contributed to the separation of FXRM from the management of other types of risks, i.e. the creation of so-called "risk management silos". Today a major trend is underway towards integrated risk management, and the firm must find ways to subordinate FXRM to this larger purpose. We argue the most promising route is to transfer responsibility for FXRM-policy from Finance/Treasury to a corporate risk function (e.g. a CRO) supported by a risk committee dedicated to integrated risk management. The same should be the case with all other main market or macro-economic related risks outside the control of business unit management. Such risks should be considered a corporate responsibility, although the specialist departments normally handling such risks, like Finance/Treasury for FX risks, should still play a role in the execution of transactions and be an important contributor in the risk committee.

We suggest that the Board of Directors have an important role in setting the company on the path towards a cost-efficient and centralized FXRM that pursues the goal of an integrated form of risk management that also preserves the firm's transparency toward the investor community. Indeed, part of the purpose of this paper has been to give directors the necessary inputs and arguments to act as agents of change in this regard. A lack of structured arguments, or 
'ammunition', is a common reason why the status quo goes unchallenged in many

organizations. The Board of Directors, however, as the designated guardians of the interests of shareholders', have the ultimate responsibility for the firm's overall risk profile and for making sure that the organization is not wasteful of its resources. Reclaiming FXRM along the lines discussed in this paper is a good way for a board to manifest its commitment to these goals. 


\section{References}

Aabo T., Fraser J., and Simkins, B. (2005), "The Rise and Evolution of the Chief Risk Officer: Enterprise Risk Management at Hydro One”. Journal Of Applied Corporate Finance. 17(3)

Aabo, T. (2015), “Corporate Hedging of Price Risks: Minimizing Variance of Eliminating Lower-Tail Outcomes?”, Journal of Applied Corporate Finance 27 (1)

Alviniussen, A. and Jankensgård, H. (2009). ”Enterprise Risk Budgeting - Bringing Risk Management into the Financial Planning Process”, Journal of Applied Finance 19 (1/2)

Alviniussen, A. and Jankensgård, H., "Have You Got the Risk Right? On Risk Appetite, Strategic Planning, and a Truly Holistic Approach to Risk Management " (March 15, 2013). Available at SSRN: http://ssrn.com/abstract $=2233830$

Alviniussen, A. and Jankensgård, H. (2014). "Value and Risk: Enterprise Risk Management at Statoil”. In Implementing Enterprise Risk Management: Cases and Best Practice, Simkins, B., Fraser, T., and Narvaez, K. (Eds.): John Wiley \& Sons, Hoboken, New Jersey

Andrén, N., Jankensgård, H., and Oxelheim, L. (2005). ”Exposure-based Cash-Flow-at-Risk: An Alternative to Value-at-Risk for Industrial Companies”, Journal of Applied Corporate Finance 17 (3)

Botosan, C. A. (2006). "Disclosure and the cost of capital: what do we know?" Accounting and Business Research 36

CFA Institute (2011), “User Perspectives on Financial Instrument Risk Disclosures Under International Financial Reporting Standards”. Discussion paper.

Chiu, H.-S., Oxelheim L., Wihlborg, C., and Zhang, J. (forthcoming), "Macroeconomic Fluctuations as Sources of Luck in CEO Compensation”, Journal of Business Ethics.

Forssbaeck, J. and L. Oxelheim (2015), “The Multifaceted Concept of Transparency”. In Forssbaeck, J. and L. Oxelheim (eds), The Oxford Handbook of Economic and Institutional Transparency, New York: Oxford University Press.

Froot, K.A. Scharfstein, D.S., and Stein, J.C. (1993), "Risk management: coordinating corporate”Investment and financing policies', Journal of Finance, 48

Frydman, C. and R. Saks (2010), "Executive compensation: A new view form a long-run perspective1936-2005”. Review of Financial Studies, 24

Jankensgård, H. (2010). “Measuring Corporate Liquidity Risk”, Journal of Applied Corporate Finance 22 (4)

Jankensgård, H. (2015). "Does Centralization of FX Derivative Usage Impact Firm Value”? European Financial Management, 15(2)

Jankensgård, H. (2014). ”A Tale of Beauties and Beasts. Testing the Optimal Disclosure Hypothesis”? Multinational Finance Journal 8 (1/2) 
Jankensgård, H. and Hagströmer, B., Asset Illiquidity and Corporate Hedging (January 27, 2011). Lund Institute of Economic Research Working Paper No. 2011/1.

Jankensgård, H., Hoffman, K., and Rahmat, D. (2014). ”Risk Disclosure, Derivative Usage, and Firm Value”. Journal of Accounting and Finance, 14 (5)

Lundqvist, S. A. (2014). “An Exploratory Study of Enterprise Risk Management Pillars of ERM”. Journal of Accounting, Auditing \& Finance, 29(3)

Nocco, B. W. and Stulz, R. M. (2006). "Enterprise Risk Management: Theory and Practice." Journal of Applied Corporate Finance 18(4)

Oxelheim, L. (1999). "Applying "MUST” analysis and the role of government in CI." Competitive Intelligence Review 10(4)

Oxelheim, L, and Wihlborg, C. (2008), Corporate Decision-making with Macroeconomic Uncertainty, New York: Oxford University Press

Oxelheim, L and Clarkson, K. (forthcoming). "Cronyism and the Determinants of Chairman Compensation”, Journal of Business Ethics.

Oxelheim, L and Thorsheim, M. (2014), “On the Propensity to Disclose Macroeconomic effects on Corporate performance”, IFN Working Paper

Oxelheim, L, Wihlborg, C. and Zhang, J. (2012), "How to avoid compensation the CEO for luck: the case of macroeconomic fluctuations”. In Thomas, R. and J. Hill (eds.) Research Handbook on Executive Pay. Cheltenham: Edward Elgars.

Oxelheim, L., and Wihlborg, C. (2003), "Recognizing Macroeconomic Fluctuations in Value Based Management”, Journal of Applied Corporate Finance, 15 (4)

Murphy, K. (2012), “The politics of pay: a legislative history of executive compensation”. In Thomas, R. and J. Hill (eds.) Research Handbook on Executive Pay. Cheltenham: Edward Elgars.

Smith, C. W. and Stulz, R. M. (1985). "The Determinants of Firms' Hedging Policies." Journal of Financial \& Quantitative Analysis 20(4): 391-405.

Wells, H. (2012), “US executive compensation in historical perspective”. In Thomas, R. and Hill, J. (eds.) Research Handbook on Executive Pay. Cheltenham: Edward Elgars 